\title{
The Age of Cyberpsychology: An Overview
}

\author{
Julie R. Ancis \\ New Jersey Institute of Technology
}

\begin{abstract}
This article serves as an overview and introduction to the discipline of cyberpsychology. Research and scholarship on the interaction of technology and human behavior through the lens of psychology has exploded, and relatedly the field of cyberpsychology. The internet has transformed social interactions, communication patterns, and even our identities. Research literature and presentations in the area of cyberpsychology have primarily attended to personality variables, perceptual processes, emotional functioning, and behavioral responses. Five major areas identified in the literature as especially relevant to the field are examined, including online behavior and personality; social media use and psychological functioning; games and gaming; telepsychology; and virtual reality, artificial intelligence, and applications. In addition, future directions in cyberpsychology as it relates to ethics, clinical work, age and disability, education and training, and research are discussed. As the field of cyberpsychology is relatively in its infancy, psychologists are well positioned to inform this innovative discipline through interdisciplinary collaborations.
\end{abstract}

Keywords: virtual reality, telepsychology, social media, virtual environments, artificial intelligence

\section{The Age of Cyberpsychology: Past, Present, and Future}

We have entered a new era in the field of psychology. Approximately 58\% of the world's 7 billion people use the internet (Clement, 2019). The creation and sharing of information and ideas through social media has become a primary form of communication and information exchange (Brossard \& Scheufele, 2013; Smith \& Anderson, 2018). The combination of new technologies and "digital natives" (Prensky, 2001), that is, those who have grown up using the internet, computers, and mobile devices, is transforming the ways in which we learn, communicate, and socialize in the world (Institute for Information Technologies in Education, 2011). Social interactions, communication, and patterns of behavior in almost every sphere of life have been transformed. Electronic messaging has become the medium of choice for business and personal communication (Srivastava, 2005). Greater convenience and extended information access related to "always on" connectivity and mobility have led to technology entering the private spheres of human lives. Users have a "technological intimacy" with many devices, carrying and

Action Editor: Danielle S. McNamara was the action editor for this article. ORCID iD: Julie R. Ancis (D) https://orcid.org/0000-0001-5314-4524. Disclosure: The author has no known conflict of interest to disclose.

Open Access License: This work is licensed under a Creative Commons Attribution-NonCommercial-NoDerivatives 4.0 International License (CC-BY-NC-ND). This license permits copying and redistributing the work in any medium or format for noncommercial use provided the original authors and source are credited and a link to the license is included in attribution. No derivative works are permitted under this license.

Disclaimer: Interactive content is included in the online version of this article.

Contact Information: Correspondence concerning this article should be addressed to Julie R. Ancis, New Jersey Institute of Technology, 431 Cullimore Hall, University Heights, Newark, NJ, USA. Email: julieancis@gmail.com using them wherever they go. Traditional hierarchical structures have flattened, accessibility to political institutions has been enhanced, and the ability to build personal and professional networks has surged. The use of mobile devices alone has decentralized communication networks and has the potential to facilitate groups of unrelated people at a moment's notice (Rheingold, 2002; Srivastava, 2005). The speed and flow of information online has enabled information to be transferred on a mass global scale, galvanizing social movements such as the Arab Spring, Occupy Wall Street, and \#MeToo. In short, the ways in which we consume information and communicate with others both locally and globally have fundamentally changed.

With the growth of new technologies and an increasingly interconnected world, the field of cyberpsychology has emerged as a unique discipline. Defined as the discipline of understanding the psychological processes related to, and underlying, all aspects and features of technologically interconnected human behavior (Atrill-Smith et al., 2019), cyberpsychology includes multiple and intersecting disciplines such as human-computer interaction, computer science, engineering, and psychology. Advances in global communication and technologies, social media and networking sites, and technological intimacy created through developments such as the iPhone have created shifts in perspectives and behaviors. Moreover, there is expanded recognition of cyberpsychology through professional associations, such as the American Psychological Association (APA), as well as via new journals, conferences, and emerging academic programs. As such, the term cyberpsychology has come to encompass diverse areas of scholarship and application which are viewed through the lens of psychology and the behavioral sciences. The transdisciplinary nature of cyberpsychology draws on a range of theoretical perspectives and continues to evolve. Moreover, the applications of cyberpsychology to a myriad of arenas such as education, healthcare, the workforce, security, and psychological practice are far reaching.

This article serves as an introduction to five major areas that have been identified as relevant to the field of cyberpsychology, including trends and directions in cyberpsychology ethics, research, training, 
and application. They include (a) online behavior and personality; (b) social media use and psychological functioning; (c) games and gaming; (d) telepsychology; and (e) virtual reality (VR), artificial intelligence (AI), and applications. These five areas emerged from a review of over 400 textbooks, including texts focused specifically on psychology and cyber, and journal articles that examined the relationship between technology and human behavior through the lens of psychology, as well as a thematic analysis of topics presented during previous APA Technology, Mind, and Society Conferences, first convened in 2018. The five areas, which have primarily attended to personality variables, perceptual processes, emotional functioning, and behavioral responses, have emerged as most prominent in the cyberpsychology literature.

It must be acknowledged that the field of cyberpsychology is in its infancy in many ways, which includes not having a definitive and agreed upon language and boundaries. This review, while not exhaustive, posits a potential framework from which to further elucidate the field of cyberpsychology through an established understanding of past and present work as well as an identification of areas in need of further exploration.

\section{Online Behavior and Personality}

As individuals increasingly engage with the world through cyber technology in many areas of their lives, research on online behavior has also increased. These investigations include the ways in which people behave in cyberspace relative to face-to-face and the relationship between personality characteristics and a range of online behavior such as social media preferences and use, dating activity, cybersecurity measures, and online bullying.

People often behave differently in cyberspace versus offline. The online disinhibition effect is a term used to describe the lowering of psychological restraints in online social environments (Joinson, 2007; Suler, 2004, 2016), reflected in reduced behavioral inhibitions and lowered regard for behavioral boundaries in cyberspace. The lack of eye contact and anonymity in cyberspace are two factors that reduce inhibitions and result in cyber-specific behavior, including self-disclosure (Lapidot-Lefler \& Barak, 2015). Individuals may engage in viewing content (e.g., pornography, violent sites) or seeking information (e.g., healthcare) online that they would not do offline.

A number of studies have explored the complex relationship between aspects of the online environment (i.e., reduced cues and controllability), personality characteristics, and online behavior ( $\mathrm{Wu}$ et al., 2017). For example, personality factors seem to be associated with Social Networking Site (SNS) preferences such as Facebook or Twitter use (Hughes et al., 2012; Lahari, 2014). Much of this research has applied studies in human personality to online behavior. For example, the Five-Factor Model of personality (neuroticism/ emotional stability, extraversion, openness to experience, agreeableness, and conscientiousness) has been applied to the investigation of people's use of SNSs through self-reports (e.g., Ross et al., 2009) as well as more objective measures of user information (Amichai-Hamburger \& Vinitzky, 2010). These five factors have been studied extensively across cultures as representing personality traits (Costa \& McCrae, 1992). Extraversion, agreeableness, and conscientiousness are positively related to social media use in many countries (Correa et al., 2010; Gil de Zúñiga et al., 2017) particularly general frequency of media use, social media news use, and online social interactions, whereas emotional stability and openness to new experiences are negatively related to social media use (Gil de Zúñiga et al., 2017). Extraversion also appears to be positively associated with the number and frequency of text messaging and communication app usage on smartphones (Harari et al., 2019; Montag et al., 2014). Other research (e.g., Fox \& Rooney, 2015; Gnambs \& Appel, 2018; Mehdizadeh, 2010) has found weak-to-moderate positive relationships between the Dark Triad of personality (i.e., narcissism, Machiavellianism, and psychopathy) and social networking behaviors. For example, high levels of narcissism are associated with greater online self-promotional behavior such as number of selfies posted as well as such as editing photographs of oneself posted on SNSs (Fox \& Rooney, 2015).

Personality features have also been shown to relate to online dating activity. A national survey of over 19,000 Americans who were married between 2005 and 2012 found that over one-third met online (Cacioppo et al., 2013). Singles who used dating apps, such as Tinder, score significantly higher on extraversion and openness to experience with medium effect sizes compared with non app users (Timmermans \& De Caluwé, 2017). Additional research has examined how relationships are developed and maintained online as well as negative aspects of online relationships such as catfishing, which is used for romantic scams.

The relationship between individual personality and online behavior such as cybersecurity measures has also been studied. Cybersecurity is an area that continues to benefit from psychological research findings (Wiederhold, 2014). For example, using a regression model, McCormac et al. (2017) found that conscientiousness, agreeableness, openness, emotional stability, and risk-taking propensity explained a significant amount of the variance in information security awareness, with conscientiousness the most important contributor, followed by agreeableness and risk-taking propensity. Similarly, characteristics such as rational decision-making and extraversion were found to be significant unique predictors of careful computer security behaviors (i.e., device securement, updating) after controlling for demographic factors such as age and gender (Gratian et al., 2018).

Other investigations have included exploring social psychological factors that contribute to online criminal activity (Kirwan \& Power, 2012; McAlaney et al., 2018) and ways in which fraudsters deceive their victims (Burgard \& Schlembach, 2013), cyberattacks, and cyber terrorism (Rogers, 2003); the social psychological impact of cybercrime victimization (Kirwan \& Power, 2012); factors that influence privacy precautions (Burgard \& Schlembach, 2013) such as perceptions of risks and rewards; and evidence-based practices for helping to raise public awareness and promote related precautions. Understanding the impact of deep fakes (Goodfellow et al., 2014) on unsuspecting victims is another important area of study which will continue to have longstanding consequences for individuals and society.

An area of online behavior which has received attention in both the popular press and among researchers is cyberbullying. Cyberbullying is defined as "willful and repeated harm inflicted through the use of computers, cell phone, or other electronic devices" (Hinduja \& Patchin, 2014). Fifty-nine percent of U.S. teens report being bullied or harassed online (Anderson, 2018). This can include sending or posting humiliating or threatening messages or photos to a third party or to a public forum where many online participants visit. The dissemination of sexually explicit images or video of an 
ex-partner via the internet is a particular form of cyberbullying, otherwise known as "revenge porn."

The cyberbullying literature has examined the prevalence of cyberbullying among youth, prevalence estimates across demographic factors (e.g., sex, race), the overlap between face-to-face bullying and cyberbullying, and predictors of cyberbullying (Espelage \& Hong, 2017; Kowalski et al., 2014). Texting and social media seem to be the most commonly used venues for cyberbullying (Whittaker \& Kowalski, 2015). Studies have shown that both Big Five and Dark Triad personality traits are related to traditional bullying and cyberbullying behaviors in adolescents as well as in adults (van Geel et al., 2017). In addition, normative beliefs about aggression, moral disengagement, callousness, and sadism are related to cyberbullying among youth (Kowalski et al., 2014; Wright et al., 2019). The psychological and behavioral impact of cyberbullying is significant. Meta-analyses have revealed associations between cyber-victimization and higher school attendance problems, academic achievement difficulties, loneliness, suicidal ideation, anxiety, and substance use with correlations ranging from .15 to .27 (Gardella et al., 2017; Kowalski et al., 2014).

Research on personality and online behavior is ripe for further investigations as qualities beyond the Five-Factor Model are considered. This includes both personality and environmental factors that influence an online disinhibition effect, particular online personas, and the regulation of online behavior. Cyberspace is a unique environment which calls for consideration of dimensions that do not necessarily relate to offline behavior. For example, the sense of anonymity online (Barlett et al., 2016) coupled with particular personality characteristics seems to contribute to cyberbullying. Further research on cyberbullying prevention, such as identifying predictors and promoting interpersonal empathy and accountability, would prove of great societal benefit as offline aggression may currently evidence in online aggression. Moreover, the limitations and ethical implications of AI and its use of big data to predict personality, preferences, and behaviors require further investigation, discussion, and oversight.

\section{Social Media Use and Psychological Functioning}

The relationship between social media use and psychological functioning, especially anxiety and depression, has demonstrated varied results. Some studies have found that social media use has a positive impact on well-being by facilitating online social connections and/or enhancing physical (offline) interactions (Wellman, 2001). For example, Facebook use is associated with perceptions of online social support (Liu \& Yu, 2013; Nabi et al., 2013). Such support seems to be related to number of Facebook friends, which, in turn, is associated with reduced stress and feelings of well-being (Nabi et al., 2013). Having a larger Twitter social network and being more active in that network seems to be particularly helpful to people with lower levels of in-person social support in alleviating depressive thoughts and symptoms (Cole et al., 2019). Relatedly, online self-disclosure seems to moderate the relationship between excessive smartphone use and stress and loneliness with significant reductions in loneliness and stress for excessive smartphone users who communicate their feelings and anxieties online, but increased stress for those who engaged in little online self-disclosure (Karsay et al., 2019).
These above studies point to the availability and use of existing resources as an important factor in the relationship between social media use and psychological functioning. This may relate to the finding of gender differences in large-scale studies (Hampton et al., 2015). For men, no relationship has been found between psychological stress and frequent use of social media, mobile phones, or the internet more broadly. However, for women, tech use seems to be related to modestly lower levels of stress. Specifically, the more pictures women share through their mobile phones, the more emails they send and receive, and the more frequently they use Twitter, the lower their reported stress. It may be that women's higher levels of perceived social support through the use of technologies moderate reductions in stress.

Other studies have indicated a negative relationship between social media use and psychological functioning (Boers et al., 2019; Brooks, 2015; Kross et al., 2013; Lin et al., 2016; Vahedi \& Saiphoo, 2018). Meta-analysis of the mental, physical, and social effects of the use of social media has found a weak-to-moderate association between smartphone use and stress and anxiety (Vahedi \& Saiphoo, 2018). A significant association has also been found between social media use and increased depression with significantly increased odds of depression and lower happiness for those in the highest quartile of use relative to those in the lower quartile of use among a range of ages (Brooks, 2015; Erceg et al., 2018; Lin et al., 2016). Longitudinal effects have been demonstrated with high mean levels of social media use among adolescents over time associated with increased depression (Boers et al., 2019). Interacting with media that promotes upward social comparisons seems to be correlated with reductions in self-esteem and, in turn, increases in depressive symptom (Boers et al., 2019).

Most digital device use is positive. However, excessive use/ misuse among some may become problematic and negatively affect educational, psychological, social, and/or physical well-being (Andreassen et al., 2016; Gentile et al., 2017; Hawi \& Samaha, 2017; Lam, 2014). Internet addiction (IA) has been defined as an inability to inhibit internet use that exerts an adverse impact on major life domains such as interpersonal relations and physical health. Many researchers assert that the definition can be explained by behaviors such as excessive use of certain applications online and unregulated/pathological/problematic hours online (Frangos et al., 2011). Prevalence estimates range between $0.7 \%$ and $27.7 \%$ of the population (Poli, 2017).

It must be recognized that IA is an emerging category and no widely agreed upon diagnostic criteria exists. Several instruments to assess IA have been developed (e.g., Hawi et al., 2019; Shaw \& Black, 2008) and different cutoffs used for various studies (Poli, 2017). A meta-analysis of 31 nations across seven world regions (Cheng \& Li, 2014) demonstrates that IA prevalence is significantly related to quality of life as measured by both subjective (life satisfaction) and objective (quality of environmental conditions) indicators. IA has been found to be comorbid with mental disorders such as attention deficit hyperactivity, anxiety, alcohol abuse, and depression (Ho et al., 2014; Waldo, 2014). Younger age, male gender, early exposure to the internet, frequency of use, and availability of time have been found to be statistically related to IA (Kawabe et al., 2016; Lam et al., 2009). Moreover, certain psychological attributes such as lower self-esteem, shyness, and loneliness are moderately to strongly associated with addictive SNS 
use (Bian \& Leung, 2015; Mahapatra, 2019; Milošević-Đorđević \& Žeželj, 2014).

Clearly, the relationship between internet use and psychological functioning is not simple and depends on factors such as how one uses it (i.e., what sites are visited) and who one interacts with (Bessière et al., 2008). Greater understanding of the directional influence of potentially problematic internet use and emotional states, including comorbidity, will allow for better diagnostic models and interventions. Research may benefit from more longitudinal research (Lam, 2014) while also controlling for variables such as type of cyber use, purpose of use, personality characteristics, and level of offline social support. Future research may help to pinpoint social and psychological factors that influence internet use among diverse individuals and groups, including frequency, particular social media sites accessed, and ways in which individuals and groups present themselves online.

\section{Games and Gaming}

The development and use of video games has grown within the last few decades. Technically, "video games" are electronic games that use visual feedback. According to the Entertainment Software Association (ESA, 2019), more than 164 million adults in the United States play video games, and three-quarters of all Americans have at least one video game player in their household. The ESA reports that 93\% of American households own a smartphone and, of those, almost half of them use it to play video games. "Gamer" communities have grown, allowing people to interact in a shared space regardless of geographical location. "Digital games" is a broader term referring to any game that is played in an electronic platform including games used for learning or health (Carras et al., 2019).

Research has focused on motivators, psychosocial impact, and the purpose and application of video games in many realms, from educational to behavior change. Research on the motivators of video game use has identified human needs for competence, social connection, and autonomy (Przybylski et al., 2010; Ryan et al., 2006). Gaming may provide social opportunities and reductions in depression, for example, for youth who have more limited social support (Kim \& Ahn, 2016). This may be due to the fact that gaming has become a social activity and many gamers play with others, either physically together or online. The use of games to improve cognitive functioning and social connection in older adults, as well as relieve symptoms of post-traumatic stress disorder (PTSD) such as intrusive memories (James et al., 2015) and depression (Russoniello et al., 2019), improve mood, and reduce stress (Russoniello et al., 2009) has also been demonstrated.

One area of controversy that has received much media attention includes the impact of violent video games on behavior. Several jurisdictions have attempted to enact laws limiting the sale of violent video games to minors. Findings of nearly 30 years of research on the effects of violent video games on aggressive, violent, or delinquent behavior are mixed (Elson \& Ferguson, 2014). Overall, there appear to be weak associations between violent video games and aggression (Carras et al., 2019), and near-zero associations when variables such as gender are included in the analysis (Ferguson, 2015). Other studies employing multiple meta-analyses of violent video game use find direct associations between violent video game use and aggressive behavior, including aggressive affect and decreased empathy, aggressive cognition, and lower levels of prosocial behavior, albeit with relatively small effect sizes (Anderson et al., 2010; APA Task Force on Violent Media, 2015). While violent video game use is a risk factor for adverse outcomes, the link between violent video game use and delinquency or criminal behavior is not yet established (Calvert et al., 2017).

In 2005, the APA adopted a Resolution on Violence in Video Games and Interactive Media. Subsequently, APA (2015) formed a Task Force on Violent Media in order to ensure that the resolution was informed by the best and most current science available. Four meta-analytic reviews examining the impact of violent video game use on a variety of negative outcomes indicated an adverse effect of violent video game use on outcomes such as aggressive behavior, aggressive cognition, aggressive affect, prosocial behavior, reduced empathy, and desensitization to aggression. All four meta-analyses reported an effect size greater than zero and a narrow range of unadjusted effect sizes (.14-.29). However, the Task Force acknowledged that the meta-analyses included very few longitudinal studies and those that did, did not consider enough time points, gender differences, and degree of exposure, or test the role of multiple risk factors or motivations for using violent games. As such, the Task Force endorsed funding of basic and intervention research to address the multiple gaps in knowledge about the effects of violent video game use. In 2020, APA provided a revision to the 2015 resolution cautioning against attributing violence to violent video games use and urging further study (APA, 2020).

Several professional organizations have considered diagnostic criteria associated with gaming. The World Health Organization (2018) considers gaming disorder (GD) a mental health condition in the International Classification of Diseases 11th Revision (ICD-11). Criteria include behavioral salience, losing interest in and reducing other recreational activities, impaired control over gaming, and continuation or escalation of gaming despite the occurrence of negative consequences. In addition, the Diagnostic and Statistical Manual of Mental Disorders (DSM-5) (American Psychiatric Association, 2013) includes internet gaming disorder (IGD) as a condition for further study. The condition consists of nine criteria, including preoccupation, withdrawal symptoms, tolerance, unsuccessful attempts to control participation, and loss of interest in previous hobbies and/or entertainment. Critics of both GD and IGD indicate that they lack basic theory, definitions, properly validated and standardized assessment tools, and a clear consensus in terms of what constitutes problematic use (Aarseth et al., 2017; Lam et al., 2009; Van Rooij \& Kardefelt-Winther, 2017). Moreover, criteria based on gambling addiction or substance use disorder may be artificially applied to gamers.

Whether GM or IGD is a distinct disorder or symptom of an underlying problem remains to be determined (Bean et al., 2017). Distinctions need to be made between those who use games excessively but not problematically and those who experience psychosocial impairment as a function of excessive game use (Kuss et al., 2017). Relatedly, APA has issued guidelines for promoting healthy technology use for children, which include discussing the benefits as well as the risks of technology (APA, 2019).

Rather than viewing video game playing as positive or negative, it may be more accurate to conceptualize gaming within a context that considers developmental age, purpose, user traits, and culture. Attention to critical factors such as game content (e.g., violent vs. nonviolent), context (e.g., solo, social competitive, social 
cooperative), and purpose are crucial to understanding the impact of game playing on psychosocial functioning (Elson et al., 2014). In addition, factors such as one-time versus repeated exposure, parental involvement and supervision, and short- or long-term effects are important to consider when understanding the effects of violent video game use (Calvert et al., 2017). Caution must be paid to pathologizing video game use which may be premature and unduly limit testing the validity of GD (Bean et al., 2017). Finally, caution must be paid around interpretations about causal versus correlational results. For example, rather than depression being interpreted as an effect of games, it may be that gaming is an outcome of poorer wellbeing (Carras et al., 2019). Ethnographic research with actual gamers is warranted to understand video game use from the perspective of those who are engaged with its use.

\section{Telepsychology}

Telepsychology is defined as the provision of psychological services using telecommunication technologies (American Psychiatric Association, 2013). Terms such as telepsychology, telemental health, e-therapy, cybertherapy, email therapy, computermediated interventions, and online therapy are oftentimes used interchangeably in the literature (Amichai-Hamburger et al., 2014). Telecommunication technologies include, but are not limited to, telephone, mobile devices, interactive videoconferencing/webcam, email, chat, text, and internet (e.g., self-help websites, blogs, and social media). These communications may be synchronous, with multiple parties communicating in real time (e.g., interactive videoconferencing, telephone), or asynchronous (e.g., email, online bulletin boards, storing and forwarding of information). Technologybased mental health interventions have the potential to transform access for those limited geographically such as persons living in rural areas, by medical condition, financial constraint, or other barriers.

While the Veterans Administration has used video teleconferencing to provide therapy for more than 20 years, more psychologists are offering telepsychology, or telemental health (Novotney, 2017). APA's Center for Workforce Studies has documented telehealth's growth. From 2000 to 2008, practicing psychologist's email use with clients for service delivery more than tripled and their use of videoconferencing with clients rose from 2\% to $10 \%$ (Morland et al., 2010).

Technological advancements have enabled new stand-alone mental and behavioral health services (e.g., therapy provided over videoconferencing) as well as augmented or extended traditional in-person services (e.g., psychoeducational materials posted online after an in-person therapy session) (Maheu et al., 2012). Psychological services may be enhanced by enabling psychologists to provide support to clients between face-to-face visits. For example, the effectiveness of a text-message-based maintenance intervention for depression (TMMI-D) has been demonstrated (Schlicker et al., 2018). With the rise in smartphone use, therapy is available through downloadable apps and related companies. The accessibility, affordability, and convenience provided by online therapy companies are appealing for many consumers, especially among generations accustomed to interactions via technology (Novotney, 2017).

Digital therapeutics, which include digital health devices, software, and applications, are designed to treat a variety of disorders such as depression, sleep disorders, substance abuse disorders, and attention-deficit/hyperactivity disorder (Weir, 2018). Technological telemental health using videoconferencing, email, real-time chats, text messaging, and telephone formats has been used effectively across a wide variety of psychotherapeutic interventions and clinical populations, including adults with anxiety and depression (Griffiths et al., 2006; Spijkerman et al., 2016), adults with panic disorder and agoraphobia (Bouchard et al., 2004), children with depression (Nelson et al., 2003), combat veterans with PTSD (Frueh et al., 2007), adolescents and adults enrolled in smoking cessation programs (Spohr et al., 2015; Woodruf et al., 2007), and adolescents with symptoms of disordered eating (Heinicke et al., 2007). While many of these studies have employed cognitive-behavioral therapy online (e.g., Bouchard et al., 2004; Frueh et al., 2007), others have used mindfulness-based interventions (e.g., Spijkerman et al., 2016).

A meta-analysis of 148 peer-reviewed publications examining the use of videoconferencing to deliver patient interventions showed high patient satisfaction, moderate-to-high clinician satisfaction, and positive clinical outcomes (Richardson et al., 2009). Moreover, several studies, including meta-analysis, have found comparable outcomes between internet-based therapy and faceto-face therapy with a range of clients and presenting issues (Barak et al., 2008; Frueh et al., 2007; Morland et al., 2010; Rees \& Maclaine, 2015). Although many of these studies used videoconferencing, similar results have also been demonstrated comparing asynchronous messaging therapy such as text messaging plus Web or in-person intervention modalities, with stand-alone faceto-face therapy (e.g., Bergström et al., 2010; Spohr et al., 2015)

In addition to the provision of psychological services, mobile phone applications have been developed to predict patients' mood, emotions, cognitive/motivational states, activities, environmental context, and social context based on phone sensor values (e.g., global positioning system, ambient light, recent calls) (Burns et al., 2011). Such context-aware mobile systems can predict the patients' categorical contextual states (e.g., location), alert them to a possible state of depression (being at home on the weekend for unexpected lengths of time), and consequently encourage activity to alleviate possible symptoms of depression.

In addition to the applications of telepsychology for a range of clinical issues, telepsychology has been used for psychoeducational purposes with positive results. This includes online interventions designed to facilitate knowledge about alcohol and drug use among teenagers resulting in improved education (Newton et al., 2009) and reductions in subsequent reported use (Schwinn et al., 2010).

There have been calls for improved telepsychology outcome research methodology, including the use of an active control condition in randomized studies, assessment of the impact of therapist effects and the clinician-client relationships, an evaluation of how technology may mediate different treatment approaches, and exploration of the limits of telepsychology such as understanding when face-to-face treatment is more appropriate.

Informed by APA standards and guidelines, including the Ethical Principles of Psychologists and Code of Conduct (APA, 2002, 2010) and the Record Keeping Guidelines (APA, 2007), APA (2013) developed guidelines for the practice of telepsychology.

Two key issues addressed by these guidelines concern (a) the psychologist's own knowledge of and competence in the provision 
of telepsychology and (b) the need to ensure that the client/patient has a full understanding of the potentially increased risks for loss of security and confidentiality when using technologies. Interjurisdictional practice, that is, familiarity and compliance with relevant laws and regulations when providing psychological services across jurisdictional and international borders, emerges as another key issue. Licensing boards generally expect the provider to be licensed in the jurisdiction in which the patient is located. However, rules regarding telepsychology practice are not uniform from state to state or comprehensive (APA Practice Organization, 2014). While some states have enacted telehealth/telemedicine laws that include psychological services, details vary in terms of how both psychological practice and telepsychology are defined, as well as psychologists' disclosure requirements. Many licensing boards expect psychologists to obtain appropriate informed consent and discuss potential risks and benefits of telehealth with patients. States vary in terms of what technologies are acceptable for coverage and reimbursement. For example, in some states telephone, fax, or email messaging is excluded, whereas interactive audio, video, or data communications are included. States have started to expand the regulatory infrastructure for telemental/telebehavioral health services. The COVID-19 health crisis resulted in legislation and guidelines that expanded psychologist's ability to provide services to clients at home during the pandemic (DeAngelis, 2020).

Telepsychology has great potential to continue to provide services to a range of diverse populations while breaking the boundaries of location, space, and even time limitations. One of the major challenges will be ensuring that trainees receive the education necessary to deliver services using rapidly changing telecommunications technology. This will require ensuring that they develop skills for not only delivering competent clinical services, but also delivering these services via a wide range of technical mediums.

\section{VR, AI, and Applications}

Developments in simulated experiences and environments via VR and AI have converged with clinical, diagnostic, and educational applications for a range of psychological and social issues. VR is an advanced form of human-computer interface that allows users to interact with and/or become immersed within a computergenerated simulated environment/virtual environment (VE). Realtime computer graphics and sensory input devices are utilized. Head-mounted displays and tracking systems are often employed to deliver computer-generated images and sounds in a virtual scene, similar to what one would see and hear in the real world. People act and respond to events and situations within VR as if these were real, also known as "presence" (Sanchez-Vives \& Slater, 2005). AI replicates or simulates human intelligence in machines whereby technological devices are programmed with the perception of a responsive being. AI includes virtual human agents such as animated avatars and robots. Immersive exposure experiences through VR and AI provide an opportunity to activate emotional and behavioral responses and modify them as needed (such as in the case of phobias and trauma/PTSD), or distract one from the real world (such as in the case of pain management).

Many researchers have argued that behaviors in virtual worlds are adequate analogues of real-life behavior (e.g., Feldon \& Kafai, 2008; Yee et al., 2007). VR applications were initially developed in the early 1990s for exposure therapy targeting anxiety disorders.
VEs and VR exposure therapy simulations have since exploded with demonstrated statistical significance and clinical effectiveness for addressing many social and psychological issues, including a range of phobias (e.g., heights, flying, spiders, small spaces, storms) (Botella et al., 2000; Miloff et al., 2019), stress management in physically ill patients (Schneider \& Workman, 1999), trauma/PTSD (Gerardi et al., 2008; Rizzo et al., 2014; Rothbaum et al., 2001), body image disturbances and eating disorders (Ferrer-García et al., 2017; Riva \& Melis, 1997), and pain reduction (Hoffman et al., 2000; Wiederhold et al., 2014). Meta-analysis of randomized control trials of virtual reality exposure therapy (VRET) for many anxiety and related disorders and depressive symptoms show moderate-to-large effects, as well as long-range effects at 6- and 12-month follow-ups (Carl et al., 2019; Deng et al., 2019). However, mixed results have been demonstrated for differential effects of VRET versus in vivo conditions.

VR has been applied to the development of a variety of skills in various contexts. The military currently uses VR to help service members with stress resilience, navigate cross-cultural interactions, and learn and develop negotiation and leadership skills (Rizzo et al., 2011). In addition, VE has been used to enhance skills in patients who experience challenges or anxieties in interpersonal communication such as children with autism (Herrera et al., 2008; Strickland, 1997) and individuals with Asperger's syndrome (Cobb et al., 2002). VR components may be utilized to allow patients to practice learned cognitive and/or behavioral skills (Amichai-Hamburger et al., 2014). VR and VEs also allow for observations in real time and with other live participants in the assessment and evaluation of attention (Rizzo et al., 2001), spatial skills (McComas et al., 1998), executive cognition skills (Pugnetti et al., 1998), social skills (Harvey et al., 2019), and interpersonal and intergroup behavior (Tawa, 2017).

Advances in AI have been applied to delivery of clinically related support services. SimCoach, for example, provides an opportunity for military service members and their families to receive self-care through an online, interactive, and virtual human agent. Virtual human agents can listen, give advice, provide links to resources, or tell a story related to the participant's experience. Robots represent the physical embodiment of AI and have been similarly used in clinical capacities. Robotherapy (Libin \& Libin, 2004) or robotassisted/enhanced therapy is "the use of robots in a personalized evidence-based psychotherapy framework...to help...psychotherapists to accomplish their clinical roles and aims" (David et al., 2014). Robots and robot-assisted therapy have diagnostic promise as well as the potential to improve the social skills of children diagnosed with autism spectrum disorder (ASD) (Esteban et al., 2017; Goodrich et al., 2012; Ramírez-Duque et al., 2020; Thill et al., 2012). In particular, studies have shown that robots may be beneficial in ASD therapies as mediators between human models/ therapists and children diagnosed with ASD (Diehl et al., 2012). Social robots have also been shown to have positive effects on the well-being of older populations in reducing loneliness and increasing social connection (Bemelmans et al., 2012). One example is a robot shaped like a baby seal, named Paro, that interacts with users to encourage positive mental effects such as encouragement, enjoyment, and relaxation. Paro is currently in use at pediatric hospitals and eldercare facilities. Interaction with Paro has been shown to improve users' moods, making them more active and communicative with each other and caregivers, and reduce stress in older users 
with long-term effects (Robinson et al., 2013; Wada et al., 2004). Critics have argued that more rigorous research is needed to clarify the effectiveness (i.e., effect size, clinical relevance) and the mechanisms of change in the case of social robots for the elderly (Broekens et al., 2009; Costescu et al., 2014). In addition, more research is needed on whether interactions with robots can be generalized to real-life interactions, such as in the case of children with autism (Ricks \& Colton, 2010).

It may be predicted that the development of credible virtual humans will lead to an array of alternative educational and therapeutic services. Some have proposed creating robots that are capable of operating autonomously in the future (Esteban et al., 2017). Ensuring that psychologists remain engaged in this work is crucial to the development and implementation of effective and ethical applications.

\section{Discussion}

The field of cyberpsychology will increasingly flourish as technology continues to develop and is utilized. It fact, new psychological phenomenon will likely emerge. The affective, cognitive, and behavioral implications of cyber on an individual, dyadic, and group level are in many ways just beginning to be researched and understood. The following sections will describe ethical considerations as well as implications for clinical work, education and training, and research in the field of cyberpsychology.

\section{Ethics}

A number of unique ethical issues may arise with research using social media data. These include the public-private domain distinction online, confidentiality and security of online data, procedures for obtaining valid consent, procedures for ensuring withdrawal rights and debriefing, levels of researcher control, and implications for scientific value and potential harm. Present-day studies such as those that use social media, smartphone capabilities, and wearable sensors to measure physical activity and diet and to assess adverse drug reactions raise new and nuanced ethical issues regarding participant privacy, informed consent, and data security (Bloss et al., 2016). The use of a range of social media sites and smartphone usage leaves behind digital footprints which have been used by companies and researchers to predict secondary data such as political views, religion, shopping preferences, well-being, sexual orientation, intelligence, and personality traits (Gladstone et al., 2019; Kosinski et al., 2013; Park et al., 2015; Settanni et al., 2018; Stachl et al., 2019). The widespread availability of extensive records of individual behavior, together with the desire to learn more about customers and citizens, presents serious challenges related to privacy and data ownership (Conway, 2014). Moreover, this has become a controversial area of study as increasingly powerful AI has been applied to masses of detailed personal data to predict a range of human behavior from consumer preferences to the likelihood of criminal activity. Ethical processes and procedures have not kept up with technological developments. New forms of research enabled by technological advances in information technology, data science, and other fields have outpaced federal regulations for the protection of human subjects (Pagoto \& Nebeker, 2019). Federal guidelines do not currently address the ethical use of social media data such as publicly available tweets in research, and IRB boards are often unprepared for these challenges.

Psychologists are well positioned to contribute to cyberpsychologyrelated research, articulate caution around the validity of this research and its applications, and help to develop guidelines for the protection of individuals and communities from potentially harmful consequences. In this vein, Pagoto and Nebeker (2019) outline specific steps the scientific community can take to ensure the ethical use of social media data in scientific research. For example, they propose collaboration across disciplines and sectors (e.g., academia, industry) to respond to rapid changes in technology. Representative disciplines would reflect behavioral science, engineering, medicine, research ethics, and law to establish and maintain standards for social media research. Another step would be to convene "technology ethics boards" in universities and other research organizations to advise scientists, research participants, Insititutional Review Boards, and the public. More conversations among funding agencies, policymakers, editors, and researchers to create the necessary infrastructure to allow for ethical and effective research are certainly needed.

Similarly, the British Psychological Society (2017) developed guidelines for internet-mediated research (IMR). BPS defines IMR broadly as "any research involving the remote acquisition of data from or about human participants using the internet and its associated technologies." The guidelines are based on four main ethics principles as outlined in the Society's Code of Human Research Ethics, that is, respect for the autonomy, privacy and dignity of individuals and communities; scientific integrity; social responsibility; and maximizing benefits and minimizing harm.

Exaggerated claims have been made about the predictive power of big data in determining a range of behavior such as recidivism rates, which impact judges' decisions around sentencing (Angwin et al., 2016), and the application of predictive policing which uses algorithms to forecast who may commit a crime and likelihood of occurrence. Despite its widespread adoption, predictive policing is subject to bias and difficult to evaluate (Braga, 2007; Shapiro, 2017; van Brakel, 2016). For example, offender-based modeling algorithms were found to misidentify low-risk black defendants as high risk and high-risk white defendants as low risk (Angwin et al., 2016). Involving psychologists in the development and assessment of these types of algorithms may help to minimize algorithmic bias.

\section{Clinical Implications}

Telepsychology is increasingly being used to diagnose, treat, monitor, and provide services to communities as smartphones, laptops, and tablet computers can easily link psychologists and other mental health professionals to clients (e.g., Sexton et al., 2012). Understanding the most effective and ethical ways to integrate technology, including mobile technology and related "apps," social media, VR, "smart homes," and wearable monitoring devices into in-person care will have continued relevance to the psychology profession.

Cultural competence will also be progressively essential to ethical and effective practice (Ancis, 2003) as psychologists utilize cyber technologies with diverse populations across the globe. In fact, interacting online or with VR may help decrease the culture-based shame and stigma that some individuals and groups experience with traditional psychotherapy (Ancis, 2004). Psychologists' sensitivity 
toward differences in exposure and attitudes toward cyber technology as a function of age, socioeconomic, and generational status is relevant to developing a therapeutic relationship and informing interventions. Moreover, understanding intergenerational differences in perceptions of appropriate communication patterns such as the use of abbreviations, memes, and emojis/bitmojis is particularly relevant in online clinical settings.

It can be predicted that ethical guidelines in the use of telepsychology will continue to expand as clinicians use technologies in an array of settings from private practice, hospitals, community mental health centers, and military centers to academia (American Psychiatric Association, 2013; APA, 2019; Campbell et al., 2018). Matters related to clinician competence, security and transmission of data, interjurisdictional practice, and informed consent will require ongoing conversations and research in order to ensure that services are being delivered both effectively and ethically. Moreover, determinations of both the strengths and limitations of online therapy such as with more serious mental health issues are crucial. The role of psychologists is imperative here as they work with technology companies to ensure the responsible provision of services that attend to these concerns.

In addition to telepsychological services, we can expect continued growth in the development of sophisticated technologies associated with VR systems. VR has the potential for addressing an even wider range of physical, emotional, social, cognitive, and psychological issues than it does currently (Rizzo \& Koenig, 2017). This includes moving from the use of mediated VR to serve as a supplement or augment therapy to more autonomous VR agents which may call for a reevaluation of therapist's roles. In the area of self-help, the internet, media (e.g., DVD), apps, and other mechanisms have led to greater accessibility of VR scenarios to the general public. These developments may require a new skill set among psychologists to accommodate changes in how services are delivered. Psychologists may be increasingly called on to serve as guides or coaches as people navigate and utilize this technology for a range of presenting problems and concerns.

In addition to treatment applications, VR and the development of cyber technologies has the potential to continue to advance diagnostic and assessment procedures. VR allows for assessment to move from a more "static" approach as currently conducted, to "dynamic" interactive testing and interventions, such as in the area of rehabilitation (Rizzo et al., 2002). The ecological validity of such testing may vastly improve as it simulates real-world scenarios (Rizzo et al., 2002).

As cyber technologies develop and become more readily available, the importance of clinicians practicing within their scope of qualifications, competence, and expertise becomes more salient. Understanding the limitations and potentially negative effects is crucial. For example, VE-related side effects have been reported in some participants such as nausea-related cybersickness and postural control and perceptual-motor disturbances associated with sensory cue incongruity (Kennedy et al., 1994; Rolland et al., 1995).

In addition to direct clinical work, the contributions of psychologists to the development of a range of cyber use guidelines are needed. This work may inform the prevention of problematic cyber use. For example, according to the APA's annual Stress in America survey (APA, 2017), 94\% of parents say they take at least one action to manage their child's technology usage during the school year. Yet, $48 \%$ indicate that regulating their child's screen time is a constant battle, and $58 \%$ indicate they worry about the influence of social media on their child's physical and mental health. Guidelines for cyber use which attend to developmental age may help with these social phenomena.

\section{Aging and Disability}

As devices such as televisions, telephones, and home security systems have become more integrated with computer networks, the ability to interact with technology becomes a necessary life skill. Technology is currently used in practically every sphere of life, including service delivery, transfer of health information, and communications. Considerations to sociodemographic factors such as age and ability are vital to ensuring accessibility for all.

Both aging and disability have implications for the use of technology. Moreover, visual, auditory, cognitive, and motor impairments and disruptions are more likely to occur with aging (Administration on Aging, 2002; Hawthorn, 2000). Persons aged 65 and over numbered 50.9 million in 2017 (the most recent year for which data are available), representing $15.6 \%$ of the population, or more than one in every seven Americans (Administration for Community Living, 2018). In 2017, 35\% of people aged 65 and over in the United States reported some type of disability (i.e., difficulty in hearing, vision, cognition, ambulation, self-care, or independent living) (Kraus et al., 2018). Older adults with a physical disability are less likely than seniors who do not face physical challenges to go online (Smith, 2014). Adaptive devices such as font enlargement software, graphical aids, or amplification systems may be needed by many individuals in order to successfully interface with technology (Harvie et al., 2016).

Technological systems are also being developed to help people successfully age by being more active, embrace healthy lifestyles, and remain socially connected. Older adults are the fastest growing computer and internet user group in both personal and workplace contexts (Wagner et al., 2010) and more than half of older adults (i.e., 65 years or older) are internet users (Roberts et al., 2018). However, older adults, especially those who are less affluent and well educated, experience greater computer anxiety, feel less confident in their computer use, and have more skeptical attitudes about the benefits of technology than younger adults (Kelley \& Charness, 1995; Marquié et al., 2002; Smith, 2014). Psychologists can take the lead in assessing the needs and preferences of diverse populations and help inform design solutions. As the population ages, psychologists must consider ways to impact the age-based digital divide. This includes working with computer developers to design technology for easier and effective use and teach people to take advantage of technologies that are available.

\section{Education and Training}

Training students in the use and integration of technology to prepare them for the future delivery of services is needed as they take on novel and expanding professional roles. This includes the application of technology for clinical services and research activities, new and evolving ethical matters, and research topics requiring further investigation. Such an endeavor will require a reexamination of traditional course curriculum and training requirements to respond to this new landscape. Fundamental questions regarding what is currently missing, what is needed, and what is no longer 
relevant must be explored. Ethics around the use of technology and social media in research and clinical settings, and effective clinical practice in telepsychology are two areas that should be incorporated into current training modules.

The use of VR, specifically virtual standardized patients who are trained to simulate a clinical presentation of a patient, has great promise for clinical training, particularly for use in clinical assessments, interviews, and diagnosis (Shute \& Ke, 2012). Psychology training programs may benefit from designing effective ways to utilize and incorporate VR in educating and supervising students.

Although beyond the scope of this article, it is likely that more course work will be delivered online in the future, including psychology undergraduate and graduate coursework. Online education has exploded as a method of teaching with a number of advantages, including reaching remote students and providing education to a wider audience (DeMillo, 2015; Schwitzer et al., 2001). Online course instruction alone or in conjunction with faceto-face meetings may be more conducive to open and honest expression and perceived as less threatening than only face-toface (Ancis, 1998, 2003; Salter et al., 2017). An instructor's attitude toward and comfort level with technology certainly plays a role in creating a space for active and effective learning. As such, psychology instructors would do well to develop related skills.

\section{Research Directions}

Developments in cyber have had a profound impact on practically every aspect of human life, including education, healthcare, the workforce, and mundane activities such as shopping. The affective, cognitive, and behavioral implications on an individual, dyadic, and group level are in many ways just beginning to be researched and understood. New phenomenon has emerged in the technical age. This includes the use of online or digital media as a substitute for inperson and offline interaction, a situation made profoundly clear during the Coronavirus pandemic. As new technology develops and is implemented, such as $5 \mathrm{G}$, novel phenomenon will emerge requiring study. This includes the impact of cyber on the labor market. What will the future of work look like with increased automation? What types of job skills will be necessary? How may psychologists best prepare individuals and communities for such changes? Additional research is also needed on the impact of social media content and form on individual's and communities' perspectives and understanding of societal issues. Questions include "How do memes impact critical thinking?," "What are the implications for informed discussions and social justice?," and "How are psychologists as consumers of social media impacted and how does this affect their research and practice?"

The field of cyberpsychology will continue to grow exponentially as technologies and associated applications change rapidly over time. There may be a tendency among some clinicians and researchers to critique the emergence of cyber in our everyday life and profession. Certainly there is room for valid criticism and concern. Cyber-related addictions, interpersonal disconnectedness, and online security threats are troubling social issues. However, cyber can also be employed for good in cases such as the use of artificial neural networks as indicators of tumors (Li et al., 2015), personalized educational materials, and social connectedness.

Psychologists, through their training and skills, are uniquely positioned to be a force for innovation and good as we navigate this new world. Moreover, 21st-century science calls for psychologists to engage in interdisciplinary work with other professionals such as computer scientists, engineers, and bioinformatics experts. Psychologists and other social scientists must take the lead in providing the necessary infrastructure to allow cyberpsychology to flourish in the most scientific and ethical way possible with applications to solving real-world problems.

\section{References}

Aarseth, E., Bean, A. M., Boonen, H., Colder Carras, M., Coulson, M., Das, D., Deleuze, J., Dunkels, E., Edman, J., Ferguson, C. J., Haagsma, M. C., Bergmark, K. H., Hussain, Z., Jansz, J., Kardefelt-Winther, D., Kutner, L., Markey, P., Nielsen, R. K. L., Prause, N., .. . Van Rooij, A. J. (2017) Scholars' open debate paper on the World Health Organization ICD-11 Gaming Disorder proposal. Journal of Behavioral Addictions, 6(3), 267 270. https://doi.org/10.1556/2006.5.2016.088

Administration for Community Living. (2018). 2018 profile of older Americans. U.S. Department of Health and Human Services.

Administration on Aging. (2002). A profile of older Americans: 2002. U.S. Department of Health and Human Services.

American Psychological Association. (2002). Ethical principles of psychologists and code of conduct. American Psychologist, 57, 1060-1073. https://doi.org/10.1037/0003-066X.57.12.1060

American Psychological Association. (2007). Record keeping guidelines. American Psychologist, 62(9), 993-1004. https://doi.org/10.1037/0003066X.62.9.993

American Psychological Association. (2010). Report of the ethics committee, 2009. American Psychologist, 65, 483-492. https://doi.org/10.1037/ a0019515

American Psychiatric Association. (2013). Diagnostic and statistical manual of mental disorders (5th ed.).

American Psychological Association. (2015). Resolution on violent video games. http://www.apa.org/about/policy/violent-video-games.aspx

American Psychological Association. (2017). Stress in America survey. https://www.apa.org/news/press/releases/2017/02/checking-devices

American Psychological Association. (2019). Digital guidelines: Promoting health technology use for children. https://www.apa.org/helpcenter/ digital-guidelines

American Psychological Association. (2020). APA resolution on violent video games: February 2020 revision to the 2015 resolution. https://www. apa.org/about/policy/resolution-violent-video-games.pdf

American Psychological Association Joint Task Force for the Development of Telepsychology Guidelines for Psychologists. (2013). Guidelines for the practice of telepsychology. American Psychologist, 68(9), 791-800. https://doi.org/10.1037/a0035001

American Psychological Association Practice Organization. (2014, Winter). Special section on telepsychology: The changing landscape of telepsychology. Good Practice, 8-22. https://www.apaservices.org/practice/ good-practice/2014-winter.pdf

American Psychological Association Task Force on Violent Media. (2015). Technical report on the review of the violent video game literature.

Amichai-Hamburger, Y., Klomek, A. B., Friedman, D., Zuckerman, O., \& Shani-Sherman, T. (2014). The future of online therapy. Computers in Human Behavior, 41, 288-294. https://doi.org/10.1016/j.chb.2014.09.016

Amichai-Hamburger, Y., \& Vinitzky, G. (2010). Social network use and personality. Computers in Human Behavior, 26(6), 1289-1295. https:// doi.org/10.1016/j.chb.2010.03.018

Ancis, J. R. (1998). Cultural competency training at a distance: Challenges and strategies. Journal of Counseling and Development, 76, 134-143. https://doi.org/10.1002/j.1556-6676.1998.tb02386.x

Ancis, J. R. (Ed.). (2004). Culturally responsive interventions: Innovative approaches to working with diverse populations. Routledge. 
Ancis, J. R. (2003). Teaching multicultural competencies using the Internet and other technologies. In D. B. Pope-Davis, H. L. K. Coleman, W. M. Liu, \& R. L. Toporek (Eds.), Handbook of multicultural competencies: In counseling \& psychology (pp. 575-587). Sage Publications. https:// doi.org/10.4135/9781452231693.n36

Anderson, C. A., Shibuya, A., Ihori, N., Swing, E. L., Bushman, B. J., Sakamoto, A., \& Saleem, M. (2010). Violent video game effects on aggression, empathy, and prosocial behavior in eastern and western countries: A meta-analytic review. Psychological Bulletin, 136(2), 151173. https://doi.org/10.1037/a0018251

Anderson, M. (2018). A majority of teens have experienced some form of cyberbullying. Pew Research Center. https://www.pewresearch.org/ internet/2018/09/27/a-majority-of-teens-have-experienced-some-form-ofcyberbullying/

Andreassen, C., Billieux, J., Griffiths, M. D., Kuss, D. J., Demetrovics, Z., Mazzoni, E., \& Pallesen, S. (2016). The relationship between addictive use of social media and video games and symptoms of psychiatric disorders: A large-scale cross-sectional study. Psychology of Addictive Behaviors, 30(2), 252-262. https://doi.org/10.1037/adb0000160

Angwin, J., Larson, J., Mattu, S., \& Kirchner, L. (2016). Machine bias. ProPublica. https://www.propublica.org/article/machine-bias-riskassessments-in-criminal-sentencing

Atrill-Smith, A., Fullwood, C., Keep, M., \& Kuss, D. J. (Eds.). (2019). The Oxford handbook of cyberpsychology. Oxford Univeristy Press. https:// www.oxfordhandbooks.com/view/10.1093/oxfordhb/9780198812746.001. 0001/oxfordhb-9780198812746

Barak, A., Hen, L., Boniel-Nissim, M., \& Shapira, N. (2008). A comprehensive review and a meta-analysis of the effectiveness of internet-based psychotherapeutic interventions. Journal of Technology in Human Services, 26(2-4), 109-160. https://doi.org/10.1080/15228830802094429

Barlett, C. P., Gentile, D. A., \& Chew, C. (2016). Predicting cyberbullying from anonymity. Psychology of Popular Media Culture, 5(2), 171-180. https://doi.org/10.1037/ppm0000055

Bean, A. M., Nielsen, R. K. L., van Rooij, A. J., \& Ferguson, C. J. (2017). Video game addiction: The push to pathologize video games. Professional Psychology, Research and Practice, 48(5), 378-389. https://doi.org/10. 1037/pro0000150

Bemelmans, R., Gelderblom, G. J., Jonker, P., \& de Witte, L. (2012). Socially assistive robots in elderly care: A systematic review into effects and effectiveness. Journal of the American Medical Directors Association, 13(2), 114-120.e1. https://doi.org/10.1016/j.jamda.2010. 10.002

Bergström, J., Andersson, G., Ljótsson, B., Rück, C., Andréewitch, S., Karlsson, A., Carlbring, P., Andersson, E., \& Lindefors, N. (2010). Internet-versus group-administered cognitive behaviour therapy for panic disorder in a psychiatric setting: A randomised trial. BMC Psychiatry, 10, Article 54. https://doi.org/10.1186/1471-244X-10-54

Bessière, K., Kiesler, S., Kraut, R., \& Boneva, B. S. (2008). Effects of internet use and social resources on changes on depression. Information Communication and Society, 11(1), 47-70. https://doi.org/10.1080/ 13691180701858851

Bian, M., \& Leung, L. (2015). Linking loneliness, shyness, smartphone addiction symptoms, and patterns of smartphone use to social capital. Social Science Computer Review, 33(1), 61-79. https://doi.org/10.1177/ 0894439314528779

Bloss, C., Nebeker, C., Bietz, M., Bae, D., Bigby, B., Devereaux, M., Fowler, J., Waldo, A., Weibel, N., Patrick, K., Klemmer, S., \& Melichar, L.(2016). Reimagining human research protections for 21st century science. Journal of Medical Internet Research, 18(12), Article e329. https://doi.org/10.2196/jmir.6634

Boers, E., Afzali, M. H., Newton, N., \& Conrod, P. (2019). Association of screen time and depression in adolescence. JAMA Pediatrics, 173(9), 853859. https://doi.org/10.1001/jamapediatrics.2019.1759
Botella, C., Baños, R. M., Villa, H., Perpiñá, C., \& García-Palacios, A. (2000). Virtual reality in the treatment of claustrophobic fear: A controlled multiple baseline design. Behavior Therapy, 3, 583-595. https://doi.org/ 10.1016/S0005-7894(00)80032-5

Bouchard, S., Paquin, B., Payeur, R., Allard, M., Rivard, V., Fournier, T., Renaud, P., \& Lapierre, J. (2004). Delivering cognitive-behavior therapy for panic disorder with agoraphobia in videoconference. Telemedicine Journal and e-Health, 10(1), 13-25. https://doi.org/10.1089/153056204773644535

Braga, A. A. (2007). The effects of hot spots policing on crime. Campbell Systematic Reviews, 3(3), 1-36. https://doi.org/10.4073/csr.2007.1

British Psychological Society. (2017). Ethics guidelines for internet-mediated research [INF206/04.2017]. https://www.bps.org.uk/sites/www.bps.org. uk/files/Policy/Policy\%20-\%20Files/Ethics\%20Guidelines\%20for\% 20Internet-mediated\%20Research\%20\%282017\%29.pdf

Broekens, J., Heerink, M., \& Rosendal, H. (2009). Assistive social robots in elderly care: A review. Gerontechnology (Valkenswaard), 8(2), 94-103. https://doi.org/10.4017/gt.2009.08.02.002.00

Brooks, S. (2015). Does personal social media usage affect efficiency and well-being? Computers in Human Behavior, 46, 26-37. https://doi.org/10. 1016/j.chb.2014.12.053

Brossard, D., \& Scheufele, D. A. (2013). Social science. Science, new media, and the public. Science, 339(6115), 40-41. https://doi.org/10.1126/ science. 1232329

Burgard, A., \& Schlembach, C. (2013). Frames of fraud: A qualitative analysis of the structure and process of victimization on the internet. International Journal of Cyber Criminology, 7(2), 112-124.

Burns, M. N., Begale, M., Duffecy, J., Gergle, D., Karr, C. J., Giangrande, E., \& Mohr, D. C. (2011). Harnessing context sensing to develop a mobile intervention for depression. Journal of Medical Internet Research, 13(3), Article e55. https://doi.org/10.2196/jmir.1838

Cacioppo, J. T., Cacioppo, S., Gonzaga, G. C., Ogburn, E. L., \& VanderWeele, T. J. (2013). Marital satisfaction and break-ups differ across on-line and off-line meeting venues. Proceedings of the National Academy of Sciences of the United States of America, 110(25), 10135-10140. https://doi.org/10.1073/pnas.1222447110

Calvert, S. L., Appelbaum, M., Dodge, K. A., Graham, S., Nagayama Hall, G. C., Hamby, S., Fasig-Caldwell, L. G., Citkowicz, M., Galloway, D. P., \& Hedges, L. V. (2017). The American Psychological Association Task Force assessment of violent video games: Science in the service of public interest. American Psychologist, 72(2), 126-143. https://doi.org/10.1037/ a0040413

Campbell, L. F., Millán, F. A., \& Martin, J. N. (Eds.). (2018). A telepsychology casebook: Using technology ethically and effectively in your professional practice. American Psychological Association. https://doi.org/ 10.1037/0000046-000

Carl, E., Stein, A. T., Levihn-Coon, A., Pogue, J. R., Rothbaum, B., Emmelkamp, P., Asmundson, G. J. G., Carlbring, P., \& Powers, M. B. (2019). Virtual reality exposure therapy for anxiety and related disorders: A meta-analysis of randomized controlled trials. Journal of Anxiety Disorders, 61, 27-36. https://doi.org/10.1016/j.janxdis.2018.08.003

Carras, M. C., Kowert, R., \& Quandt, T. (2019). Psychosocial effects of gaming. In A. Atrill-Smith, C. Fullwood, M. Keep, \& D. J. Kuss (Eds.), The Oxford handbook of cyberpsychology (pp. 557-587). Oxford Univeristy Press. https://doi.org/10.1093/oxfordhb/9780198812746.013.30

Cheng, C., \& Li, A. Y. (2014). Internet addiction prevalence and quality of (real) life: A meta-analysis of 31 nations across seven world regions. Cyberpsychology, Behavior, and Social Networking, 17(12), 755-760. https://doi.org/10.1089/cyber.2014.0317

Clement, J. (2019). Worldwide digital population as of October 2019. https:// www.statista.com/statistics/617136/digital-population-worldwide/\#: : targetText=How\%20many\%20people $\% 20$ use $\% 20$ the,in $\% 20$ terms $\% 20$ of $\% 20$ internet $\% 20$ users

Cobb, S., Beardon, L., Eastgate, R., Glover, T., Kerr, S., Neale, H., Parsons, S., Benford, S., Hopkins, E., Mitchell, P., Reynard, G., \& Wilson, J. 
(2002). Applied virtual environments to support learning of social interaction skills in users with Asperger's Syndrome. Digital Creativity, 13(1), 11-22. https://doi.org/10.1076/digc.13.1.11.3208

Cole, D. A., Nick, E. A., Varga, G., Smith, D., Zelkowitz, R. L., Ford, M. A., \& Lédeczi, Á. (2019). Are aspects of Twitter use associated with reduced depressive symptoms? The moderating role of in-person social support. Cyberpsychology, Behavior, and Social Networking, 22(11), 692-699. https://doi.org/10.1089/cyber.2019.0035

Conway, M. (2014). Ethical issues in using Twitter for public health surveillance and research: Developing a taxonomy of ethical concepts from the research literature. Journal of Medical Internet Research, 16(12), Article e290. https://doi.org/10.2196/jmir.3617

Correa, T., Hinsley, A. W., \& de Zúñiga, H. G. (2010). Who interacts on the Web?: The intersection of users' personality and social media use. Computers in Human Behavior, 26(2), 247-253. https://doi.org/10. 1016/j.chb.2009.09.003

Costa, P. T., Jr., \& McCrae, R. R. (1992). Four ways five factors are basic. Personality and Individual Differences, 13(6), 653-665. https://doi.org/ 10.1016/0191-8869(92)90236-I

Costescu, C. A., Vanderborght, B., \& David, D. O. (2014). The effects of robot-enhanced psychotherapy: A meta-analysis. Review of General Psychology, 18(2), 127-136. https://doi.org/10.1037/gpr0000007

David, D., Matu, S.-A., \& David, O. A. (2014). Robot-based psychotherapy: Concepts development, state of the art, and new directions. International Journal of Cognitive Therapy, 7(2), 192-210. https://doi.org/10.1521/ijct. 2014.7.2.192

DeAngelis, T. (2020). What the COVID-19 telehealth waiver means for psychology practitioners. https://www.apaservices.org/practice/legal/ technology/covid-19-telehealth-waiver

DeMillo, R. (2015). Revolution in higher education: How a small band of innovators will make college accessible and affordable. MIT Press.

Deng, W., Hu, D., Xu, S., Liu, X., Zhao, J., Chen, Q., Liu, J., Zhang, Z., Wenxiu, J., Ma, L., Hong, X., Cheng, S., Liu, B., \& Li, X. (2019). The efficacy of virtual reality exposure therapy for PTSD symptoms: A systematic review and meta-analysis. Journal of Affective Disorders, 257, 698-709. https://doi.org/10.1016/j.jad.2019.07.086

Diehl, J. J., Schmitt, L. M., Villano, M., \& Crowell, C. R. (2012). The clinical use of robots for individuals with Autism Spectrum Disorders: A critical review. Research in Autism Spectrum Disorders, 6(1), 249-262. https:// doi.org/10.1016/j.rasd.2011.05.006

Elson, M., Breuer, J., \& Quandt, T. (2014). Know thy player: An integrated model of player experience for digital games research. In M. C. Angelides (Ed.), Handbook of digital games (pp. 362-387). Wiley. https://doi.org/ 10.1002/9781118796443.ch13

Elson, M., \& Ferguson, C. J. (2014). Twenty-five years of research on violence in digital games and aggression: Empirical evidence, perspectives, and a debate gone astray. European Psychologist, 19(1), 33-46. https://doi.org/10.1027/1016-9040/a000147

Entertainment Software Association. (2019). Essential facts about the computer and video game industry. https://www.theesa.com/esa-research/ 2019-essential-facts-about-the-computer-and-video-game-industry/

Erceg, T., Buligan Flander, G. B., \& Brezinšćak, T. (2018). The relationship between compulsive internet use and symptoms of depression and anxiety in adolescence. Alcoholism and Psychiatry Research, 54, 101-112. https:// doi.org/10.20471/dec.2018.54.02.02

Espelage, D. L., \& Hong, J. S. (2017). Cyberbullying prevention and intervention efforts: Current knowledge and future directions. Canadian Journal of Psychiatry, 62(6), 374-380. https://doi.org/10.1177/ 0706743716684793

Esteban, P. G., Baxter, P., Belpaeme, T., Billing, E., Cai, H., Cao, H.-L., Coeckelbergh, M., Costescu, C., David, D., De Beir, A., Fang, Y., Ju, Z., Kennedy, J., Liu, H., Mazel, A., Pandey, A., Richardson, K., Senft, E., Thill, S., ... Ziemke, T. (2017). How to build a supervised autonomous system for robot-enhanced therapy for children with Autism Spectrum
Disorder. Paladyn: Journal of Behavioral Robotics, 8(1), 18-38. https:// doi.org/10.1515/pjbr-2017-0002

Feldon, D. F., \& Kafai, Y. B. (2008). Mixed methods for mixed reality: Understanding users' avatar activities in virtual worlds. Educational Technology Research and Development, 56, 575-593. https://doi.org/ 10.1007/s11423-007-9081-2

Ferguson, C. J. (2015). Do angry birds make for angry children? A metaanalysis of video game influences on children's and adolescents' aggression, mental health, prosocial behavior, and academic performance. Perspectives on Psychological Science, 10(5), 646-666. https://doi.org/ 10.1177/1745691615592234

Ferrer-García, M., Gutiérrez-Maldonado, J., Pla-Sanjuanelo, J., VilaltaAbella, F., Riva, G., Clerici, M., Ribas-Sabaté, J., Andreu-Gracia, A., Fernandez-Aranda, F., Forcano, L., Riesco, N., Sánchez, I., EscandónNagel, N., Gomez-Tricio, O., Tena, V., \& Dakanalis, A. (2017). A randomized controlled comparison of second-level treatment approaches for treatment-resistant adults with bulimia-nervosa and binge eating disorder: Assessing the benefits of virtual reality cue exposure therapy. European Eating Disorders Review, 25(6), 479-490. https://doi.org/10. 1002/erv. 2538

Fox, J., \& Rooney, M. C. (2015). The dark triad and trait self-objectification as predictors of men's use and self-presentation behaviors on social networking sites. Personality and Individual Differences, 76, 161-165. https://doi.org/10.1016/j.paid.2014.12.017

Frangos, C. C., Frangos, C. C., \& Sotiropoulos, I. (2011). Problematic internet use among Greek university students: An ordinal logistic regression with risk factors of negative psychological beliefs, pornographic sites, and online games. Cyberpsychology, Behavior, and Social Networking, 14(1-2), 51-58. https://doi.org/10.1089/cyber.2009.0306

Frueh, B. C., Monnier, J., Yim, E., Grubaugh, A. L., Hamner, M. B., \& Knapp, R. G. (2007). A randomized trial of telepsychiatry for posttraumatic stress disorder. Journal of Telemedicine and Telecare, 13(3), 142-147. https://doi.org/10.1258/135763307780677604

Gardella, J. H., Fisher, B. W., \& Teurbe-Tolon, A. R. (2017). A systematic review and meta-analysis of cyber-victimization and educational outcomes for adolescents. Review of Educational Research, 87(2), 283308. https://doi.org/10.3102/0034654316689136

Gentile, D. A., Bailey, K., Bavelier, D., Brockmyer, J. F., Cash, H., Coyne, S. M., Doan, A., Grant, D. S., Shawn Green, C., Griffiths, M., Markle, T., Petry, N. M., Prot, S., Rae, C. D., Rehbein, F., Rich, M., Sullivan, D., Woolley, E., \& Young, K. (2017). Internet Gaming Disorder in children and adolescents. Pediatrics, 140(Suppl 2), S81-S85. https://doi.org/10. 1542/peds.2016-1758H

Gerardi, M., Rothbaum, B. O., Ressler, K., Heekin, M., \& Rizzo, A. (2008). Virtual reality exposure therapy using a virtual Iraq: Case report. Journal of Traumatic Stress, 21(2), 209-213. https://doi.org/10.1002/jts.20331

Gil de Zúñiga, H., Diehl, T., Huber, B., \& Liu, J. (2017). Personality traits and social media use in 20 countries: How personality relates to frequency of social media use, social media news use, and social media use for social interaction. Cyberpsychology, Behavior, and Social Networking, 20(9), 540-552. https://doi.org/10.1089/cyber.2017.0295

Gladstone, J. J., Matz, S. C., \& Lemaire, A. (2019). Can psychological traits be inferred from spending? Evidence from transaction data. Psychological Science, 30(7), 1087-1096. https://doi.org/10.1177/0956797619849435

Gnambs, T., \& Appel, M. (2018). Narcissism and social networking behavior. Journal of Personality, 86(2), 200-212. https://doi.org/10. 1111/jopy.12305

Goodfellow, I., Pouget-Abadie, J., Mirza, M., Xu, B., Warde-Farley, D., Ozair, S., Courville, A., \& Bengio, Y. (2014). Generative adversarial nets. In Z. Ghahramani, M. Welling, C. Cortes, N. D. Lawrence, \& K. Q. Weinberger (Eds.), Advances in neural information processing systems (Vol. 27, pp. 2672-2680). Curran Associates. http://papers.nips.cc/paper/ 5423-generative-adversarial-nets.pdf 
Goodrich, M. A., Colton, M., Brinton, B., Fujiki, M., Atherton, J. A., Robinson, L., Ricks, D., Maxfield, M. H., \& Acerson, A. (2012). Incorporating a robot into an autism therapy team. IEEE Intelligent Systems, 27(2), 52-59. https://doi.org/10.1109/MIS.2012.40

Gratian, M., Bandi, S., Cukier, M., Dykstra, J., \& Ginther, A. (2018). Correlating human traits and cyber security behavior intentions. Computers \& Security, 73, 345-358. https://doi.org/10.1016/j.cose. 2017.11.015

Griffiths, L., Blignault, I., \& Yellowlees, P. (2006). Telemedicine as a means of delivering cognitive-behavioural therapy to rural and remote mental health clients. Journal of Telemedicine and Telecare, 12(3), 136-140. https://doi.org/10.1258/135763306776738567

Hampton, K., Ranie, L., Lu, W., Shin, I., \& Purcell, K. (2015). Social media and the cost of caring: Psychological stress and social media use. Pew Research Center. https://www.pewresearch.org/internet/2015/01/15/ psychological-stress-and-social-media-use-2/

Harari, G. M., Müller, S. R., Stachl, C., Wang, R., Wang, W., Bühner, M., Rentfrow, P. J., Campbell, A. T., \& Gosling, S. D. (2019). Sensing sociability: Individual differences in young adults' conversation, calling, texting, and app use behaviors in daily life. Journal of Personality and Social Psychology, 119(1), 204-228. https://doi.org/10. 1037/pspp0000245

Harvey, P. D., Khan, A., Atkins, A., \& Keefe, R. S. E. (2019). Virtual reality assessment of functional capacity in people with Schizophrenia: Associations with reduced emotional experience and prediction of functional outcomes. Psychiatry Research, 277(277), 58-63. https://doi.org/ 10.1016/j.psychres.2019.01.045

Harvie, G., Eustace, K., \& Burmeister, O. K. (2016). Assistive technology devices for the oldest-old: Maintaining independence for the fourth age. In D. Kreps, G. Fletcher, \& M. Griffiths (Eds.), Technology and intimacy: Choice or coercion (pp. 25-33). Springer International Publishing. https:// doi.org/10.1007/978-3-319-44805-3_3

Hawi, N. S., \& Samaha, M. (2017). Relationships among smartphone addiction, anxiety, and family relations. Behaviour \& Information Technology, 36(10), 1046-1052. https://doi.org/10.1080/0144929X. 2017.1336254

Hawi, N. S., Samaha, M., \& Griffiths, M. D. (2019). The digital addiction scale for children: Development and validation. Cyberpsychology, Behavior, and Social Networking, 22(12), 771-778. https://doi.org/10. 1089/cyber.2019.0132

Hawthorn, D. (2000). Possible implications of aging for interface designers. Interacting with Computers, 12(5), 507-528. https://doi.org/10.1016/ S0953-5438(99)00021-1

Heinicke, B. E., Paxton, S. J., McLean, S. A., \& Wertheim, E. H. (2007). Internet-delivered targeted group intervention for body dissatisfaction and disordered eating in adolescent girls: A randomized controlled trial. Journal of Abnormal Child Psychology, 35, 379-391. https://doi.org/10. 1007/s10802-006-9097-9

Herrera, G., Alcantud, F., Jordan, R., Blanquer, A., Labajo, G., \& De Pablo, C. (2008). Development of symbolic play through the use of virtual reality tools in children with autistic spectrum disorders: Two case studies. Autism: The International Journal of Research and Practice, 12(2), 143-157. https://doi.org/10.1177/1362361307086657

Hinduja, S., \& Patchin, J. W. (2014). Bullying beyond the schoolyard: Preventing and responding to cyberbullying (2nd ed.). Corwin.

Ho, R. C., Zhang, M. W., Tsang, T. Y., Toh, A. H., Pan, F., Lu, Y., Cheng, C., Yip, P. S., Lam, L. T., Lai, C.-M., Watanabe, H., \& Mak, K.-K. (2014). The association between internet addiction and psychiatric co-morbidity: A meta-analysis. BMC Psychiatry, 14(1), Article 183. https://doi.org/10. 1186/1471-244X-14-183

Hoffman, H. G., Doctor, J. N., Patterson, D. R., Carrougher, G. J., \& Furness, T. A., III. (2000). Virtual reality as an adjunctive pain control during burn wound care in adolescent patients. Pain, 85(1-2), 305-309. https:// doi.org/10.1016/S0304-3959(99)00275-4
Hughes, D. J., Rowe, M., Batey, M., \& Lee, A. (2012). A tale of two sites: Twitter vs. Facebook and the personality predictors of social media usage. Computers in Human Behavior, 28(2), 561-569. https://doi.org/10.1016/ j.chb.2011.11.001

Institute for Information Technologies in Education. (2011). Digital natives: How do they learn? How to teach them? UNESCO. https://iite.unesco.org/ files/policy_briefs/pdf/en/digital_natives.pdf

James, E. L., Bonsall, M. B., Hoppitt, L., Tunbridge, E. M., Geddes, J. R., Milton, A. L., \& Holmes, E. A. (2015). Computer game play reduces intrusive memories of experimental trauma via reconsolidation-update mechanisms. Psychological Science, 26(8), 1201-1215. https://doi.org/ 10.1177/0956797615583071

Joinson, A. N. (2007). Disinhibition and the internet. In J. Gackenbach (Ed.), Psychology and the internet: Intrapersonal, interpersonal, and transpersonal implications (pp. 75-92). Academic Press. https://doi.org/10.1016/ B978-012369425-6/50023-0

Karsay, K., Schmuck, D., Matthes, J., \& Stevic, A. (2019). Longitudinal effects of excessive smartphone use on stress and loneliness: The moderating role of self-disclosure. Cyberpsychology, Behavior, and Social Networking, 22(11), 706-713. https://doi.org/10.1089/cyber.2019.0255

Kawabe, K., Horiuchi, F., Ochi, M., Oka, Y., \& Ueno, S. (2016). Internet addiction: Prevalence and relation with mental states in adolescents. Psychiatry and Clinical Neurosciences, 70(9), 405-412. https://doi.org/ 10.1111/pcn. 12402

Kelley, C. L., \& Charness, N. (1995). Issues in training older adults to use computers. Behaviour \& Information Technology, 14(2), 107-120. https:// doi.org/10.1080/01449299508914630

Kennedy, R. S., Berbaum, K. S., \& Drexler, J. (1994). Methodological and measurement issues for identification of engineering features contributing to virtual reality sickness. Proceedings of the IMAGE VII Conference (pp. 244-254). IMAGE Society.

Kim, H. H., \& Ahn, S. J. (2016). How does neighborhood quality moderate the association between online video game play and depression? A population-level analysis of Korean students. Cyberpsychology, Behavior, and Social Networking, 19(10), 628-634. https://doi.org/10.1089/cyber. 2016.0155

Kirwan, G., \& Power, A. (Eds.). (2012). The psychology of cyber crime: Concepts and principles. IGI Global. https://doi.org/10.4018/978-161350-350-8

Kosinski, M., Stillwell, D., \& Graepel, T. (2013). Private traits and attributes are predictable from digital records of human behavior. Proceedings of the National Academy of Sciences of the United States of America, 110(15), 5802-5805. https://doi.org/10.1073/pnas.1218772110

Kowalski, R. M., Giumetti, G. W., Schroeder, A. N., \& Lattanner, M. R. (2014). Bullying in the digital age: A critical review and meta-analysis of cyberbullying research among youth. Psychological Bulletin, 140(4), 1073-1137. https://doi.org/10.1037/a0035618

Kraus, L., Lauer, E., Coleman, R., \& Houtenville, A. (2018). 2017 disability statistics annual report. University of New Hampshire.

Kross, E., Verduyn, P., Demiralp, E., Park, J., Lee, D. S., Lin, N., Shablack, H., Jonides, J., \& Ybarra, O. (2013). Facebook use predicts declines in subjective well-being in young adults. PLOS ONE, 8(8), Article e69841. https://doi.org/10.1371/journal.pone.0069841

Kuss, D. J., Griffiths, M. D., \& Pontes, H. M. (2017). DSM-5 diagnosis of Internet Gaming Disorder: Some ways forward in overcoming issues and concerns in the gaming studies field. Journal of Behavioral Addictions, 6(2), 133-141. https://doi.org/10.1556/2006.6.2017.032

Lahari, D. K. (2014). Study of neuroticism on usage and preference of social networking sites as a function of educational background and gender. Impact. International Journal of Research in Humanities, Arts, and Literature, 2(7), 91-96.

Lam, L. T. (2014). Risk factors of Internet addiction and the health effect of internet addiction on adolescents: A systematic review of longitudinal and 
prospective studies. Current Psychiatry Reports, 16, Article 508. https:// doi.org/10.1007/s11920-014-0508-2

Lam, L. T., Peng, Z. W., Mai, J. C., \& Jing, J. (2009). Factors associated with Internet addiction among adolescents. Cyberpsychology \& Behavior, 12(5), 551-555. https://doi.org/10.1089/cpb.2009.0036

Lapidot-Lefler, N., \& Barak, A. (2015). Effects of anonymity, invisibility, and lack of eye-contact on toxic online disinhibition. Computers in Human Behavior, 28(2), 434-443. https://doi.org/10.1016/j.chb.2011.10.014

Li, W., Jia, F., \& Hu, Q. (2015). Automatic segmentation of liver tumor in CT images with deep convolutional neural networks. Journal of Computer and Communications, 3, 146-151. https://doi.org/10.4236/jcc.2015.311023

Libin, A. V., \& Libin, E. V. (2004). Person-robot interactions from the robopsychologists' point of view: The robotic psychology and robotherapy approach. Proceedings of the IEEE, 92(11), 1789-1803. https:// doi.org/10.1109/JPROC.2004.835366

Lin, L. Y., Sidani, J. E., Shensa, A., Radovic, A., Miller, E., Colditz, J. B., Hoffman, B. L., Giles, L. M., \& Primack, B. A. (2016). Association between social media use and depression among U.S. young adults. Depression and Anxiety, 33(4), 323-331. https://doi.org/10.1002/ da. 22466

Liu, C. Y., \& Yu, C. P. (2013). Can Facebook use induce well-being? Cyberpsychology Behavior, and Social Networking, 16(9), 674-678. https://doi.org/10.1089/cyber.2012.0301

Mahapatra, S. (2019). Smartphone addiction and associated consequences: Role of loneliness and self-regulation. Behaviour \& Information Technology, 38(8), 833-844. https://doi.org/10.1080/0144929X.2018. 1560499

Maheu, M. M., Pulier, M. L., McMenamin, J. P., \& Posen, L. (2012). Future of telepsychology, telehealth, and various technologies in psychological research and practice. Professional Psychology, Research and Practice, 43, 613-621. https://doi.org/10.1037/a0029458

Marquié, J. C., Jourdan-Boddaert, L., \& Huet, N. (2002). Do older adults underestimate their actual computer knowledge? Behaviour \& Information Technology, 21(4), 273-280. https://doi.org/10.1080/ 0144929021000020998

McAlaney, J., Frumkin, L. A., \& Benson, V. (Eds.). (2018). Psychological and behavioral examinations in cyber security. IGI Global. https://doi.org/ 10.4018/978-1-5225-4053-3

McComas, J., Pivik, J., \& Laflamme, M. (1998). Current uses of virtual reality for children with disabilities. Studies in Health Technology and Informatics, 58, 161-169. https://doi.org/10.3233/978-1-60750-9028-1611

McCormac, A., Zwaans, T., Parsons, K., Dragana, C., Butavicius, M., \& Pattison, M. (2017). Individual differences and information security awareness. Computers in Human Behavior, 69, 151-156. https:// doi.org/10.1016/j.chb.2016.11.065

Mehdizadeh, S. (2010). Self-presentation 2.0: Narcissism and self-esteem on Facebook. Cyberpsychology, Behavior, and Social Networking, 13(4), 357-364. https://doi.org/10.1089/cyber.2009.0257

Miloff, A., Lindner, P., Dafgård, P., Deak, S., Garke, M., Hamilton, W., Heinsoo, J., Kristoffersson, G., Rafi, J., Sindemark, K., Sjölund, J., Zenger, M., Reuterskiöld, L., Andersson, G., \& Carlbring, P. (2019). Automated virtual reality exposure therapy for spider phobia vs. in-vivo one-session treatment: A randomized non-inferiority trial. Behaviour Research and Therapy, 118, 130-140. https://doi.org/10.1016/j.brat. 2019.04.004

Milošević-Đorđević, J. S., \& Žeželj, I. L. (2014). Psychological predictors of addictive social networking sites use: The case of Serbia. Computers in Human Behavior, 32, 229-234. https://doi.org/10.1016/j.chb.2013.12.018 Montag, C., Błaszkiewicz, K., Lachmann, B., Andone, I., Sariyska, R., Trendafilov, B., Reuter, M., \& Markowetz, A. (2014). Correlating personality and actual phone usage: Evidence from psychoinformatics. Journal of Individual Differences, 35(3), 158-165. https://doi.org/10. 1027/1614-0001/a000139
Morland, L. A., Greene, C. J., Rosen, C. S., Foy, D., Reilly, P., Shore, J., He, Q., \& Frueh, B. C. (2010). Telemedicine for anger management therapy in a rural population of combat veterans with posttraumatic stress disorder: A randomized noninferiority trial. The Journal of Clinical Psychiatry, 71(7), 855-863. https://doi.org/10.4088/JCP.09m05604blu

Nabi, R. L., Prestin, A., \& So, J. (2013). Facebook friends with (health) benefits? Exploring social network site use and perceptions of social support, stress, and well-being. Cyberpsychology, Behavior, and Social Networking, 16(10), 721-727. https://doi.org/10.1089/cyber.2012.0521

Nelson, E. L., Barnard, M., \& Cain, S. (2003). Treating childhood depression over videoconferencing. Telemedicine Journal and e-Health, 9(1), 49-55. https://doi.org/10.1089/153056203763317648

Newton, N. C., Andrews, G., Teesson, M., \& Vogl, L. E. (2009). Delivering prevention for alcohol and cannabis using the Internet: A cluster randomised controlled trial. Preventive Medicine, 48, 579-584. https://doi.org/ 10.1016/j.ypmed.2009.04.009

Novotney, A. (2017). A growing wave of online therapy. Monitor on Psychology, 48(2), 48. https://www.apa.org/monitor/2017/02/onlinetherapy

Pagoto, S., \& Nebeker, C. (2019). How scientists can take the lead in establishing ethical practices for social media research. Journal of the American Medical Informatics Association, 26(4), 311-313. https:// doi.org/10.1093/jamia/ocy 174

Park, G., Schwartz, H. A., Eichstaedt, J. C., Kern, M. L., Kosinski, M., Stillwell, D. J., Unger, L. H., \& Seligman, M. E. P. (2015). Automatic personality assessment through social media language. Journal of Personality and Social Psychology, 108(6), 934-952. https://doi.org/10. 1037/pspp0000020

Poli, R. (2017). Internet addiction update: Diagnostic criteria, assessment and prevalence. Neuropsychiatry, 7(1), 4-8. https://doi.org/10.4172/ Neuropsychiatry.1000171

Prensky, M. (2001). Digital natives, digital immigrants. On the Horizon, 9(5), 1-6. https://doi.org/10.1108/10748120110424816

Przybylski, A. K., Rigby, C. S., \& Ryan, R. M. (2010). A motivational model of video game engagement. Review of General Psychology, 14(2), 154 166. https://doi.org/10.1037/a0019440

Pugnetti, L., Mendozzi, L., Attree, E. A., Barbieri, E., Brooks, B., Cazzullo, C. L., Motta, A., Rose, F. D., \& Psychol, C. (1998). Probing memory and executive functions with virtual reality: Past and present studies. Cyberpsychology \& Behavior, 1(2), 151-161. https://doi.org/10.1089/ cpb.1998.1.151

Ramírez-Duque, A. A., Bastos, T., Munera, M., Cifuentes, C. A., \& FrizeraNeto, A. (2020). Robot-Assisted Intervention for children with special needs: A comparative assessment for autism screening. Robotics and Autonomous Systems, 127, Article 103484. https://doi.org/10.1016/j. robot.2020.103484

Rees, C. S., \& Maclaine, E. (2015). A Systematic review of videoconferencedelivered psychological treatment for anxiety disorders: Videoconferenced treatment for anxiety disorders. Australian Psychologist, 50(4), 259-264. https://doi.org/10.1111/ap.12122

Rheingold, H. (2002). Smart mobs (pp. 189-202). Demos.

Richardson, L. K., Frueh, B. C., Grubaugh, A. L., Egede, L., \& Elhai, J. D. (2009). Current directions in videoconferencing tele-mental health research. Clinical Psychology: Science and Practice, 16(3), 323-338. https://doi.org/10.1111/j.1468-2850.2009.01170.x

Ricks, D. J., \& Colton, M. B. (2010). Trends and considerations in robotassisted autism therapy. IEEE International Conference on Robotics and Automation, pp. 4354-4359. https://doi.org/10.1109/ROBOT.2010. 5509327

Riva, G., \& Melis, L. (1997). Virtual reality for the treatment of body image disturbances. Studies in Health Technology and Informatics, 44, 95-111.

Rizzo, A., Hartholt, A., Grimani, M., Leeds, A., \& Liewer, M. (2014). Virtual reality exposure therapy for combat-related Posttraumatic Stress Disorder. Computer, 47(7), 31-37. https://doi.org/10.1109/MC.2014.199 
Rizzo, A., Lange, B., Buckwalter, J. G., Forbell, E., Kim, J., Sagae, K., Williams, J., Difede, J., Rothbaum, B. O., Reger, G., Parsons, T., \& Kenny, P. (2011). SimCoach: An intelligent virtual human system for providing healthcare information and support. International Journal on Disability and Human Development: IJDHD, 10(4), 277-281. https:// doi.org/10.1515/IJDHD.2011.046

Rizzo, A. A., Buckwalter, J. G., Bowerly, T., Humphrey, L. A., Ulrich, N., van Rooyen, A., \& Kim, L. (2001). The virtual classroom: A virtual reality environment for the assessment and rehabilitation of attention deficits. Revista Española de Neuropsicología, 3(3), 11-37.

Rizzo, A. A., Buckwalter, J. G., \& van der Zaag, C. (2002). Virtual environment applications for neuropsychological assessment and rehabilitation. In K. Stanney (Ed.), Handbook of virtual environments (pp. 10271064). Lawrence Erlbaum Associates.

Rizzo, A. S., \& Koenig, S. T. (2017). Is clinical virtual reality ready for primetime? Neuropsychology, 31(8), 877-899. https://doi.org/10.1037/ neu0000405

Roberts, A., Ogunwole, S., Blakeslee, L., \& Rabe, M. (2018). A snapshot of the fast-growing U.S. older population. Most older adults live in households with computer and internet access. United States Census Bureau.

Robinson, H., Macdonald, B., Kerse, N., \& Broadbent, E. (2013). The psychosocial effects of a companion robot: A randomized controlled trial. Journal of the American Medical Directors Association, 14(9), 661-667. https://doi.org/10.1016/j.jamda.2013.02.007

Rogers, M. (2003). The psychology of cyber-terrorism. In A. Silke (Ed.), Terrorists, victims and Society: Psychological perspectives on terrorism and its consequences (pp. 77-92). Wiley. https://doi.org/10.1002/ 9780470713600.ch4

Rolland, J. P., Biocca, F. A., Barlow, T., \& Kancherla, A. (1995). Quantification of adaptation to virtual-eye location in see-thru headmounted displays [Symposium]. Proceedings of the IEEE Virtual Reality Annual International Symposium '95 (pp. 55-66). IEEE Computer Society Press. https://doi.org/10.1109/VRAIS.1995.512480

Ross, C., Orr, E. S., Sisic, M., Arseneault, J. M., Simmering, M. G., \& Orr, R. R. (2009). Personality and motivations associated with Facebook use. Computers in Human Behavior, 25(2), 578-586. https://doi.org/10.1016/ j.chb.2008.12.024

Rothbaum, B. O., Hodges, L. F., Ready, D., Graap, K., \& Alarcon, R. D. (2001). Virtual reality exposure therapy for Vietnam veterans with posttraumatic stress disorder. The Journal of Clinical Psychiatry, 62, 617-622. https://doi.org/10.4088/JCP.v62n0808

Russoniello, C., O’Brien, K., \& Parks, J. M. (2009). The effectiveness of casual video games in improving mood and decreasing stress. Journal of Cyber Therapy and Rehabilitation, 2, 53-66.

Russoniello, C. V., Fish, M. T., \& O'Brien, K. (2019). The efficacy of playing videogames compared with antidepressants in reducing treatmentresistant symptoms of depression. Games for Health Journal, 8(5), 332338. https://doi.org/10.1089/g4h.2019.0032

Ryan, R. M., Rigby, C. S., \& Przybylski, A. (2006). The motivational pull of video games: A self-determination theory approach. Motivation and Emotion, 30(4), 344-360. https://doi.org/10.1007/s11031-006-9051-8

Salter, S., Douglas, T., \& Kember, D. (2017). Comparing face-to-face and asynchronous online communication as mechanisms for critical reflective dialogue. Educational Action Research, 25(5), 790-805. https://doi.org/ 10.1080/09650792.2016.1245626

Sanchez-Vives, M. V., \& Slater, M. (2005). From presence to consciousness through virtual reality. Nature Reviews Neuroscience, 6(4), 332-339. https://doi.org/10.1038/nrn1651

Schlicker, S., Ebert, D. D., Middendorf, T., Titzler, I., \& Berking, M. (2018). Evaluation of a text-message-based maintenance intervention for major depressive disorder after inpatient cognitive behavioral therapy. Journal of Affective Disorders, 227, 305-312. https://doi.org/10.1016/j.jad.2017. 10.047
Schneider, S. M., \& Workman, M. L. (1999). Effects of virtual reality on symptom distress in children receiving chemotherapy. Cyberpsychology \& Behavior, 2(2), 125-134. https://doi.org/10.1089/cpb.1999.2.125

Schwinn, T. M., Schinke, S. P., \& Di Noia, J. (2010). Preventing drug abuse among adolescent girls: Outcome data from an internet-based intervention. Prevention Science: The Official Journal of the Society for Prevention Research, 11, 24-32. https://doi.org/10.1007/s11121-009-0146-9

Schwitzer, A. M., Ancis, J. R., \& Brown, N. (2001). Promoting student learning and student development at a distance: Student affairs concepts and practices for televised instruction and other forms of distance learning. University Press of America.

Settanni, M., Azucar, D., \& Marengo, D. (2018). Predicting individual characteristics from digital traces on social media: A meta-analysis. Cyberpsychology, Behavior, and Social Networking, 21(4), 217-228. https://doi.org/10.1089/cyber.2017.0384

Sexton, T. L., Patterson, T., \& Datchi, C. C. (2012). Technological innovations of systematic measurement and clinical feedback: A virtual leap into the future of couple and family psychology. Couple \& Family Psychology, 1(4), 285-293. https://doi.org/10.1037/cfp0000001

Shapiro, A. (2017). Reform predictive policing. Nature, 541, 458-460. https://doi.org/10.1038/541458a

Shaw, M., \& Black, D. W. (2008). Internet addiction: Definition, assessment, epidemiology and clinical management. CNS Drugs, 22, 353-365. https:// doi.org/10.2165/00023210-200822050-00001

Shute, V. J., \& Ke, F. (2012). Games, learning, and assessment. In D. Ifenthaler, D. Eseryel, \& X. Ge (Eds.), Assessment in game-based learning (pp. 43-58). Springer. https://doi.org/10.1007/978-1-4614-3546-4_4

Smith, A. (2014). Older adults and internet use. Pew Research Center.

Smith, A., \& Anderson, M. (2018). Social media use 2018: Demographics and statistics. Pew Research Center: Internet, Science \& Tech. https:// www.pewresearch.org/internet/2018/03/01/social-media-use-in-2018/

Spijkerman, M. P. J., Pots, W. T. M., \& Bohlmeijer, E. T. (2016). Effectiveness of online mindfulness-based interventions in improving mental health: A review and meta-analysis of randomised controlled trials. Clinical Psychology Review, 45, 102-114. https://doi.org/10. 1016/j.cpr.2016.03.009

Spohr, S. A., Nandy, R., Gandhiraj, D., Vemulapalli, A., Anne, S., \& Walters, S. T. (2015). Efficacy of SMS text message interventions for smoking cessation: A meta-analysis. Journal of Substance Abuse Treatment, 56, 1-10. https://doi.org/10.1016/j.jsat.2015.01.011

Srivastava, L. (2005). Mobile phones and the evolution of social behaviour. Behaviour \& Information Technology, 24(2), 111-129. https://doi.org/10. 1080/01449290512331321910

Stachl, C., Au, Q., Schoedel, R., Buschek, D., Völkel, S., Schuwerk, T., Oldemeier, M., Ullmann, T., Hussmann, H., Bischl, B., \& Bühner, M. (2019). Behavioral patterns in smartphone usage predict Big Five personality. PsyArXiv traits. https://doi.org/10.31234/osf.io/ks4vd

Strickland, D. (1997). Virtual reality for the treatment of autism. In G. Riva (Ed.), Virtual Reality in Neuro-Psycho-Physiology (pp. 81-86). IOS Press.

Suler, J. (2004). The online disinhibition effect. Cyberpsychology \& Behavior, 7(3), 321-326. https://doi.org/10.1089/1094931041291295

Suler, J. R. (2016). Psychology of the digital age: Humans become electric. Cambridge University Press. https://doi.org/10.1017/ CBO9781316424070

Tawa, J. (2017). Asymmetric peer selections among Blacks, Asians, and Whites in a virtual environment: Preliminary evidence for triangulated threat theory. The Journal of Social Psychology, 157(6), 736-753. https:// doi.org/10.1080/00224545.2017.1294140

Thill, S., Pop, C. A., Belpaeme, T., Ziemke, T., \& Vanderborght, B. (2012). Robot-assisted therapy for Autism Spectrum Disorders with (Partially) autonomous control: Challenges and outlook. Paladyn: Journal of Behavioral Robotics, 3(4), 209-217. https://doi.org/10.2478/s13230013-0107-7 
Timmermans, E., \& De Caluwé, E. (2017). To Tinder or not to Tinder, that's the question: An individual differences perspective to Tinder use and motives. Personality and Individual Differences, 110, 74-79. https:// doi.org/10.1016/j.paid.2017.01.026

Vahedi, Z., \& Saiphoo, A. (2018). The association between smartphone use, stress, and anxiety: A meta-analytic review. Stress and Health, 34(3), 347358. https://doi.org/10.1002/smi.2805

van Brakel, R. (2016). Pre-emptive big data surveillance and its (dis) empowering consequences: The case of predictive policing. SSRN Electronic Journal. https://doi.org/10.2139/ssrn.2772469

van Geel, M., Goemans, A., Toprak, F., \& Vedder, P. (2017). Which personality traits are related to traditional bullying and cyberbullying? A study with the Big Five, Dark Triad and sadism. Personality and Individual Differences, 106, 231-235. https://doi.org/10.1016/j.paid. 2016.10.063

Van Rooij, A. J., \& Kardefelt-Winther, D. (2017). Lost in the chaos: Flawed literature should not generate new disorders. Journal of Behavioral Addictions, 6(2), 128-132. https://doi.org/10.1556/2006.6.2017.015

Wada, K., Shibata, T., Saito, T., \& Tanie, K. (2004). Effects of robot-assisted activity for elderly people and nurses at day service center. Proceedings of the IEEE, 92(11), 1780-1788. https://doi.org/10.1109/JPROC.2004. 835378

Wagner, N., Hassanein, K., \& Head, M. (2010). Computer use by older adults: A multi-disciplinary review. Computers in Human Behavior, 26(5), 870-882. https://doi.org/10.1016/j.chb.2010.03.029

Waldo, A. D. (2014). Correlates of internet addiction among adolescents. Psychology (Irvine, Calif.), 05(18), 1999-2008. https://doi.org/10.4236/ psych.2014.518203

Weir, K. (2018). The ascent of digital therapies: Evidence-based apps could enhance-and in some cases, replace medications for treating a range of mental health disorders. Monitor on Psychology, 49(10). https://www.apa. org/monitor/2018/11/cover-digital-therapies

Wellman, B. (2001). Computer networks as social networks. Science, 293, 2031-2034. https://doi.org/10.1126/science.1065547
Whittaker, E., \& Kowalski, R. M. (2015). Cyberbullying via social media. Journal of School Violence, 14(1), 11-29. https://doi.org/10.1080/ 15388220.2014 .949377

Wiederhold, B. K. (2014). The role of psychology in enhancing cybersecurity. Cyberpsychology, Behavior, and Social Networking, 17(3), 131132. https://doi.org/10.1089/cyber.2014.1502

Wiederhold, B. K., Gao, K., Sulea, C., Wiederhold, M. D. (2014). Virtual reality as a distraction technique in chronic pain patients. CyberPsychology, Behavior \& Social Networking, 17(6), 346-352. https:// doi.org/10.1089/cyber.2014.0207.

Woodruf, S. I., Conway, T. L., Edwards, C. A., \& Elliott, S. P. (2007). Evaluation of an internet world chat room for adolescent smoking cessation. Addictive Behaviors, 32(9), 1769-1786. https://doi.org/10. 1016/j.addbeh.2006.12.008

World Health Organization. (2018). International classification of diseases for mortality and morbidity statistics (11th Revision). https://icd.who.int/ browse11/1-m/en

Wright, M. F., Harper, B. D., \& Wachs, S. (2019). The associations between cyberbullying and callous-unemotional traits among adolescents: The moderating effect of online disinhibition. Personality and Individual Differences, 140(1), 41-45. https://doi.org/10.1016/j.paid.2018.04.001

Wu, S., Lin, T. C., \& Shih, J. F. (2017). Examining the antecedents of online disinhibition. Information Technology \& People, 30(1), 189-209. https:// doi.org/10.1108/ITP-07-2015-0167

Yee, N., Bailenson, J. N., Urbanek, M., Chang, F., \& Merget, D. (2007). The unbearable likeness of being digital: The persistence of nonverbal social norms in online virtual environments. Cyberpsychology \& Behavior, 10(1), 115-121. https://doi.org/10.1089/cpb.2006.9984

Received April 21, 2020

Revision received July 08, 2020

Accepted July 23, 2020 